\title{
Low incidence of schizophrenia in British Columbia coastal Indians
}

\author{
CHARLES E BATES ${ }^{1}$ AND CARLA H VAN DAM 2 \\ From BX 273 Merville, ${ }^{1}$ British Columbia VOR 2MO, and North Island College, ${ }^{2}$ Campbell River, British \\ Columbia V9W 2E4, Canada
}

SUMMARY Schizophrenia rates were obtained from a British Columbia coastal Indian group numbering 14000 . One subgroup numbering 12200 showed an incidence of 10 cases per 100000 population a year. An atypical subgroup of 1800 showed an incidence of 49 cases per 100000 a year. These rates appear to be relevant to a hypothesis that suggests that schizophrenia may be caused by abnormal fatty acid metabolism. A study is reviewed which implies the existence of a delta-5 or delta- 6 desaturase enzyme mutation or both, in the Indian population under study.

There is disagreement regarding the incidence and prevalence of schizophrenia. The statistic cited most often is a $1 \%$ expectancy of a person getting the disease. This is reported as remarkably stable across cultures and races, more stable than for almost any other disease. Incidence is reported as $\mathbf{5 0}$ new cases per 100000 population a year and prevalence as 150 cases per 100000 population at any given time. ${ }^{1}$ These rates are also reported to be dramatically stable worldwide.

Published epidemiological reports suggest otherwise. Over 300 studies show rates that vary greatly. The Irish have an expectancy rate of over $4 \%$, based on admissions to hospital and European diagnostic criteria. The same studies, using broader north American criteria, would generate much higher rates, as would the inclusion of patients treated on an outpatient basis. Certain areas of Scandinavia and Croatia have even higher rates, whereas other countries such as Japan report expectancies under $1 \% .^{23}$ These dramatically contrasting rates follow patterns that support some explanations of the disease. Torrey surveyed published reports and concluded that these patterns are consistent with changes in diet interacting with genetic predispositions. He noted that an enzymatic defect might explain epidemiological differences among groups. ${ }^{2}$

One group of scientists have hypothesised the existence of an enzymatic defect in schizophrenics. Horrobin et al have suggested that schizophrenia may be caused by a mutation that changes the affinity of delta-5 and delta- 6 desaturase enzymes from the $\mathrm{n} 3$ to the n6 series essential fatty acids (EFAs). change would account for the low concentrations of linoleic acid, dihomogammalinolenic acid, and 1 series prostaglandins that have been reported in schizophrenia. It would also explain the high concentrations of arachidonic and alpha-linolenic acids and the recently described therapeutic response to alpha-linolenic acid.

Horrobin et al also hypothesise that seashore dwellers subsisting on rich $\mathbf{n} 3$ fatty acid sources might evolve differently from inlanders. They suggest that the delta-5 and delta- 6 desaturase enzymes might switch their affinity from the $n 3$ to the $n 6$ fatty acids, thus making it possible for shore dwellers to make more efficient use of scarce $n 6$ fatty acid sources.

British Columbia coastal Indians have such an evolutionary history. For over 10000 years they have been living on a diet consisting primarily of salmon, a fish exceptionally rich in the $n 3$ series EFAs. If shore dwellers evolving on a low $n 6$, high $n 3$ diet could have their metabolism shaped then these Indians might exhibit the type of enzyme mutation that Horrobin et al hypothesised.

The schizophrenia rates of coastal Indians were studied. Fatty acid concentrations in total phospholipids were also measured in a representative sample of these Indians. The details of that study are reported separately, but will be summarised here after reporting on the epidemiology of schizophrenia in British Columbia coastal Indians (C E Bates et al, submitted for publication). 


\section{Method}

Altogether 12200 British Columbia coastal Indians living on Vancouver Island and nearby mainland inlets were studied. They are part of a Federal Health administrative region. Every hospital admission and diagnosis is recorded by the Federal Health Ministry. Ruth Elvie, British Columbia regional psychologist, collected all forms with psychiatric diagnoses for the past eight years. Any diagnosis remotely resembling schizophrenia was counted. This generated the incidence rate.

One control group consisted of 460000 Caucasians treated by the same doctors. Schizophrenia rates for this group were extracted from computerised data at the British Columbia Ministry of Health. Once again, the broadest possible definition of schizophrenia was used, all subcategories of the diagnosis being counted. These statistics mixed new cases with return patients. The resulting rate was therefore some point between incidence and prevalence.

Another control group consisted of 1800 Cowichan Band Indians. This group is atypical in terms of genetic history, assimilation into the general Canadian culture, lack of a tidal fishing fleet, and the consequent destruction of the traditional diet. Doctors treating this group were typical of those in the rest of the region.

A third control group consisted of the patients at Riverview, the central psychiatric hospital in British Columbia. It was thought that if Indian schizophrenics somehow escaped the attention of local medical authorities owing to some tendency to leave home communities some cases would eventually be treated there.

Another place where Indian schizophrenics could escape notice would be Vancouver's skid row. Social workers and street workers were interviewed. Indian inhabitants of skid row were interviewed and blood was collected from a random sample. The subsequent fatty acid analysis was examined for schizophrenic-like imbalances.

Several other attempts were made to control for contamination of the statistics. These measures will be reviewed in the results section.

In a part of the study reported elsewhere (C E Bates et al, submitted for publication) blood was collected from random samples of three different groups: 20 Indians of pure race consuming the traditional diet, five skid row alcoholic pure race Indians not consuming the traditional diet, and four healthy mixed race Indians not consuming the traditional diet.

\section{Results}

The survey of all admissions to hospital for the population of 12200 Indians showed 10 diagnoses of schizophrenia over the past eight years, an incidence of 10 cases per 100000 population a year.

Caucasians diagnosed as schizophrenic by these same physicians during one year of that period numbered 607 out of a population of about 460000 . This is a rate of 134 cases per 100000 a year. Because new admissions were mixed with repeat patients, this rate should be regarded as a mixture of incidence and prevalence.

One band in the region, the Cowichan Band, was calculated separately. This community produced seven cases in a population of 1800 over the eight year period, an incidence of 49 cases per 100000 population a year.

Riverview, the central British Columbia psychiatric hospital, admits about 700 patients each year. Admissions administrators cannot recall any admissions of coastal Indians in recent years. Since there are about 40000 coastal Indians, many in areas lacking psychiatric wards, Riverview could be expected to admit numerous coastal Indian schizophrenics, especially if these patients tended to gravitate to Vancouver. If coastal Indians had average incidence rates, about 20 new cases of schizophrenia should surface each year.

Whereas there are many skid row Indians, social workers and street workers characterise them as having alcohol problems rather than psychoses. Dozens of Indians were interviewed and blood samples were collected from a random sample. Withdrawn behaviour was observed, but fatty acid concentrations in even the most uncommunicative subjects showed imbalances the very opposite of those found in schizophrenics (C E Bates et al, submitted for publication).

Indian mores and religion might interpret psychotic behaviour in mystical terms. But the traditional Indian mysticism is largely a thing of the past. Typical Indians belong to Caucasian churches, watch television, and live in frame houses. Traditional dances are performed, but the attitude of the average Indian is a basic acceptance of European reality. Television has seen to that. We have lived on a representative coastal reserve for over a year and believe that inappropriate or bizarre behaviour is regarded as exactly that by the community.

Do mentally ill Indians avoid medical help? Not in our experience, or in the experience of each reserve doctor interviewed. Ruth Elvie, the federal psychologist for the region under study, reports that there is an overutilisation of medical services. She says that the clinic or hospital is the social focal point 
of the community. It cannot be assumed that mentally ill Indians would avoid medical treatment.

St Joseph's Hospital in Courtenay, British Columbia, provides several medical services not available to outlying reserve hospitals and clinics. About $60 \%$ of the Indian population under study resides in the catchment area served by this hospital. Don Brown, administrator of the hospital, prepares demographic statistics on hospital use. He reports that outlying reserves fully use special medical services such as ophthalmology, otolaryngology, and others. St Joseph's has the only psychiatric ward on the north end of Vancouver Island. This is the one medical service that is not often used by Indians. Three Indian schizophrenics have been admitted in the past eight years.

Most reserve doctors enjoy high prestige in coastal communities. Interviews with several people familiar with coastal medical services showed that this pattern is repeated on numerous reserves. All doctors and administrators interviewed scoffed at the idea that Indians would avoid medical consultation for incapacitating mental problems. Such consultations are taking place every day without generating diagnoses of schizophrenia.

Blood was collected from 29 Indians with the expectation that fatty acid imbalances would be found that would point towards a delta-5 or delta- 6 desaturase mutation, changing the $\mathrm{n} 3$ affinity to an $\mathrm{n} 6$ affinity. Such a mutation would manifest itself in several possible imbalances, the most likely being raised arachidonic acid concentrations, especially in Indians not consuming the traditional diet. Instead, imbalances were found to be the opposite of those predicted. All 29 subjects had exceptionally low arachidonic acid concentrations, independent of diet.

\section{Discussion}

An incidence of 10 cases per 100000 population a year is as low as any schizophrenia rate reported. If these data have indeed escaped contamination then British Columbia coastal Indians may have something important to teach us about schizophrenia. We hope that this paper will spark further study of that group. Why the Cowichan Band should have average rates is not clear, but this band has helped to show that physicians can and do diagnose Indian schizophrenia.

Coastal Indians have arthritic disease rates 14 times higher than Caucasians. ${ }^{5}$ They appear to possess an enzyme mutation that severely lowers arachidonic acid, implying low prostaglandin E2 (PGE2) concentrations as well. The PGE2 inhibitors used to treat arthritis would seem to be contraindicated for this group. The enzyme mutation is currently being studied in greater detail, but it appears that the delta-5 or delta- 6 desaturase enzymes or both are either inactive or missing altogether. Since PGE2 and arachidonic acid concentrations are raised in schizophrenics, low arachidonic acid concentrations may explain the coastal Indians' seeming immunity to the disease.

Though the blood results seem to contradict some implications of the hypothesis of Horrobin et al, a slight modification of that model can reconcile the data with the theory. Primitive diets supply EFAs lacking in modern food. For instance, wild game supplies many EFAs unavailable in feedlot beef. ${ }^{\circ}$ Delta-5 and delta- 6 desaturase enzyme activity might have existed primarily for the metabolism of $n 3$ EFAs, crucial n6 EFAs being supplied directly by diet. If this were the case coastal dwellers, with a rich supply of all n3 EFAs, would see redundant enzyme activity disappear. The first step in that direction would be a loss in $\mathrm{n} 3$ affinity, making greater quantities of enzyme available for $n 6$ metabolism. This stage could create the imbalances found in schizophrenics. A later stage would be the loss of the enzyme activity, resulting in imbalances found on the British Columbia coast.

The Celtic Irish lived on rich $\mathbf{n} 3$ fatty acid seafood diets, not unlike those of the British Columbia Indians, for well over 10000 years. Could their extremely high rates of schizophrenia be caused by an evolutionary process only partly completed? Irish fatty acid concentrations are presently being measured with a view to exploring this possibility.

We gratefully acknowledge the generous help in gathering statistical data that we received from Ruth Elvie, BC regional psychologist, Federal Health and Welfare, Drs Jack Kyle, provincial field services advisor, BC Ministry of Health, Walter Goresky, provincial consultant in psychiatry, BC Ministry of Health, Robin Boraston, chief of staff, psychiatry, St Joseph's Hospital, and David Usher. We thank Alexander Slade, extension librarian at the University of Victoria, for his help. And the paper would have been impossible without the advice of $\mathrm{Dr}$ David Horrobin, director of research, Efamol Research, and the encouragement of Dr David Wolfe, particle physics, CERN.

\section{References}

${ }^{1}$ Crocetti GM, Lemkau PV. Epidemiology of schizophrenia. In: Freedman AM, Kaplan HF, eds. Comprehensive textbook of psychiatry. Baltimore: Williams and Wilkins, 1967: 599-603.

${ }^{2}$ Torrey EF. Schizophrenia and civilisation. New York: Jason Aronson, 1980. 
${ }^{3}$ Crocetti GM, Kulcan Z, Kesic B, Lemkau PV. Differential rates of schizophrenia in Croatia, Yugoslavia. Am J Public Health 1964; 54: 196-206.

4 Horrobin DF, Huang YS. Schizophrenia: the role of abnormal essential fatty acid and prostaglandin metabolism. Med Hypothesis 1983; 10: 329-336.
${ }^{5}$ Atkins CJ, Caira L, Ward RH, et al. Unusual rheumatic diseases in the Nootka Indians of BC. British Columbia Medical Journal 1982; 24: 20-3.

${ }^{6}$ Crawford MA. Fatty-acid ratios in free living and domestic animals: possible implications for atheroma. Lancet 1968; i: 1329-33. 